\title{
Advances in the Management of Multiple Sclerosis Spasticity: Recent Clinical Trials
}

\author{
Oscar Fernández \\ Neurology Department and Institute of Clinical Neurosciences, Regional University Hospital, Málaga, Spain
}

\author{
Key Words \\ Cognition · Mood · Pivotal trial · Phase 4 study $\cdot$ Spasticity . \\ THC:CBD oromucosal spray
}

\begin{abstract}
Background: Most patients with multiple sclerosis (MS) experience spasticity as the clinical course evolves. Associated symptoms include (often painful) spasms, urinary dysfunction and sleep disturbances. THC:CBD oromucosal spray (Sativex ${ }^{\circledR}$ ) is approved for symptom improvement in adult patients with moderate to severe MS-related spasticity who have not responded adequately to other antispasticity medication and who demonstrate clinically significant improvement in spasticity-related symptoms during an initial trial of therapy. Summary: In pivotal clinical trials of THC:CBD oromucosal spray, a meaningful proportion of patients with treatment-resistant MS spasticity achieved clinically relevant improvement with active treatment versus placebo. The utility of a 4-week trial of therapy to identify patients who respond to treatment was demonstrated in an enriched-design study. THC:CBD oromucosal spray was well tolerated in these studies, with no evidence of effects typically associated with recreational cannabis use. In a subsequent post approval clinical trial, THC:CBD oromucosal spray had no statistically significant effect on cognition and mood compared with placebo. Moreover, after 50 weeks' treatment, approximately two-thirds of patients, physicians and caregivers reported improvement from baseline in spasticity based on global impressions of change. Key Messages: In phase III
\end{abstract}

clinical trials, approximately one-third of MS patients with treatment-resistant spasticity had a clinically relevant and statistically significant response to $\mathrm{THC}: \mathrm{CBD}$ oromucosal spray. In addition to a reduction in spasticity, responders experienced meaningful relief from associated symptoms. THC:CBD oromucosal spray was generally well tolerated and efficacy was maintained over the longer term. A post-approval clinical trial indicated no effect of THC:CBD oromucosal spray on cognition or mood after 50 weeks of use.

(c) 2014 S. Karger AG, Basel

\section{Introduction}

Spasticity is a common and frequently disabling complication of multiple sclerosis (MS) and its prevalence increases as MS evolves; after 9-10 years of MS, approximately $50 \%$ of patients have greater than mild spasticity and $30 \%$ have greater than moderate spasticity [1]. MS patients with spasticity experience significantly worse symptomatology in terms of spasms, urinary dysfunction and sleep disturbances than those without spasticity [2].

THC:CBD oromucosal spray $\left(\right.$ Sativex ${ }^{\circledR}$ ) is indicated for symptom improvement in adult patients with moderate to severe MS spasticity who have not responded adequately to other antispasticity medication and who demonstrate clinically significant improvement in spasticity-related symptoms during an initial 4-week trial of therapy. In the $\mathrm{EU}$, treatment algorithms for management of MS spasticity include the use of THC:CBD oromucosal spray $[3,4]$.

\section{KARGER}

E-Mail karger@karger.com

www.karger.com/ene (c) 2014 S. Karger AG, Basel

0014-3022/14/0721-0009\$39.50/0
Dr. O. Fernández

Neurology Department, Hospital Regional Universitario de Málaga

Universidad de Málaga

Avda. de Carlos Haya s/n, 29010 Málaga (Spain)

E-Mail oscar.fernandez.sspa@juntadeandalucia.es 


\section{Pivotal Studies of THC:CBD Oromucosal Spray}

The THC:CBD oromucosal spray clinical trials program included three large pivotal phase III trials involving MS patients with treatment-resistant spasticity [5-7] (table 1). In the first two studies, mean changes from baseline in scores on the spasticity 0-10 numerical rating scale (NRS) were in favor of THC:CBD oromucosal spray compared with placebo, but differences between treatments did not reach statistical significance in the intent-to-treat populations $[5,6]$. Subsequent responder analyses indicated that 40\% [5] and $36 \%$ [6] of patients, respectively, treated with THC:CBD oromucosal spray had achieved the threshold for clinically relevant improvement $(\geq 30 \%$ NRS improvement from baseline) in the spasticity 0-10 NRS score.

An enriched-design study demonstrated the utility of a trial of therapy approach to identify responders to THC:CBD oromucosal spray [7]. After a 4-week trial of therapy with active medication, $47 \%$ of patients were initial responders ( $\geq 20 \%$ NRS improvement). At the end of the 12-week, randomized, double-blind phase, the NRS score had improved a further 0.04 points in the group treated with THC:CBD oromucosal spray and deteriorated 0.81 points in the group assigned to placebo; the difference was highly significant $(\mathrm{p}=0.0002)$. Moreover, the proportion of clinically relevant responders at week 12 was significantly higher with THC:CBD oromucosal spray than with placebo ( 74 vs. $51 \% ; \mathrm{p}=0.0003$ ).

THC:CBD oromucosal spray was well tolerated in pivotal studies. Dizziness and fatigue were the most common treatment-related adverse events but were generally mild and resolved quickly; withdrawal rates due to adverse events were low. The incidence of adverse events was further reduced by introduction of a gradual 'up titration' schedule. Importantly, in clinical trials of THC:CBD oromucosal spray, there was no evidence of effects typically associated with recreational cannabis use.

\section{Effect on Cognition and Mood}

The effects of THC:CBD oromucosal spray on cognition and mood were investigated in a randomized, double-blind, parallel-group, post-approval study in 120 patients with at least moderate MS spasticity [8]. After 50 weeks' treatment with THC:CBD oromucosal spray or placebo, no statistically differences were observed be-
Table 1. Pivotal studies of THC:CBD oromucosal spray for MS spasticity

\begin{tabular}{|c|c|c|c|}
\hline Reference & $\begin{array}{l}\text { Duration, } \\
\text { week }\end{array}$ & $\begin{array}{l}\text { Patients, } \\
\mathrm{n}\end{array}$ & $\begin{array}{l}\text { Primary endpoint: mean change from } \\
\text { baseline on spasticity } 0-10 \text { NRS }\end{array}$ \\
\hline [5] & 6 & 189 & -1.1 vs. $-0.6 \mathrm{PBO}(\mathrm{p}=0.048 ; \mathrm{ITT})$ \\
\hline$[6]$ & 14 & 337 & -1.0 vs. $-0.8 \mathrm{PBO}(\mathrm{p}=0.219 ; \mathrm{ITT})$ \\
\hline$[7]$ & $4+12$ & 572 & $\begin{array}{l}\text { Trial of therapy phase: reduction on } \\
\text { NRS from } 6.9 \text { to } 3.9 \text { in initial } \\
\text { responders }(\mathrm{n}=272) \text {. } \\
\text { Double-blind phase: }-0.04 \text { vs. }+0.81 \\
\text { PBO }(\mathrm{p}=0.0002 ; \text { ITT }) .\end{array}$ \\
\hline
\end{tabular}

ITT $=$ Intent-to treat; NRS = numerical rating scale; $\mathrm{PBO}=$ placebo.

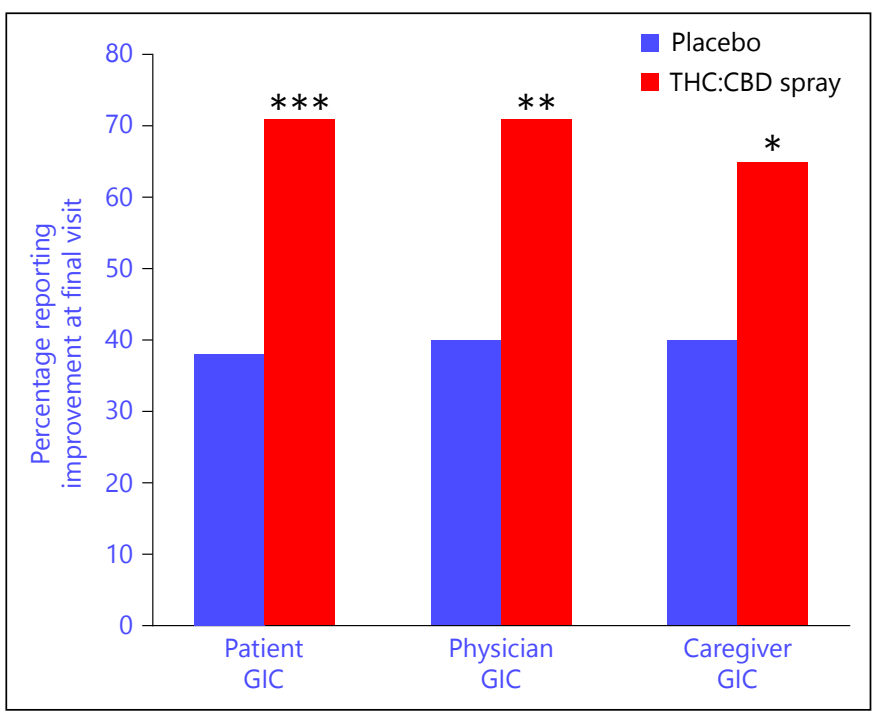

Fig. 1. Patient, physician, and caregiver global impression of change (GIC) in spasticity after 50 weeks' treatment with THC:CBD oromucosal spray or placebo [8]. ${ }^{* * *} \mathrm{p}<0.001$; ${ }^{* *} \mathrm{p}=0.0014$; $^{*} \mathrm{p}=$ 0.0042 .

tween treatment groups for change from baseline in the Paced Auditory Serial Addition Test (cognitive ability) or the Beck Depression Inventory (mood). Patient, physician and caregiver Global Impression of Change scores indicated that efficacy was maintained over the long term (fig. 1). THC:CBD oromucosal spray was well tolerated; the most common adverse events during 50 weeks of use were vertigo, dizziness, fatigue and muscle spasticity. Study withdrawals were few and similar for THC:CBD oromucosal spray and placebo (12 vs. 11 patients).
Fernández 


\section{Disclosures/Conflict of Interest}

OF has received honoraria as a consultant on advisory boards and as chairman or lecturer in meetings, and has also participated or is currently participating in clinical trials and other research projects promoted by Actelion Pharmaceuticals Ltd, Allergan,
Almirall SA, Biogen-Idec Inc, Bayer-Schering, Merck Serono, Novartis Pharmaceuticals Corporation, Teva Neuroscience Inc.

Writing assistance was provided by Content Ed Net (Madrid, Spain), with funding from Laboratorios Almirall SA (Barcelona, Spain).

\section{References}

1 Kister I, Bacon TE, Chamot E, Salter AR, Cutter GR, Kalina JT, Herbert J: Natural history of multiple sclerosis symptoms. Int J MS Care 2013;15:146-158.

2 Oreja-Guevara C: Clinical efficacy and effectiveness of Sativex, a combined cannabinoid medicine, in multiple sclerosis-related spasticity. Expert Rev Neurother 2012;12(suppl 4):3-8.

3 DGN/KKNMS Leitlinie zur Diagnose und Therapie der MS. Guidelines for MS diagnosis and treatment, 2012. Available at: http://www. dmsg.de/dokumentearchiv/dgnkknms msll_20120412_final.pdf [Accessed June 2014].
-4 Oreja-Guevara C, Montalban X, de Andrés C, Casanova-Estruch B, Muñoz-García D, García I, Fernández Ó; Grupo de Enfermedades Desmielinizantes de la Sociedad Española de Neurología: Consensus document on spasticity in patients with multiple sclerosis. Grupo de Enfermedades Desmielinizantes de la Sociedad Española de Neurología [Article in Spanish]. Rev Neurol 2013;57:359-373.

$\checkmark 5$ Collin C, Davies P, Mutiboko IK, Ratcliffe S; Sativex Spasticity in MS Study Group: Randomized controlled trial of cannabis-based medicine in spasticity caused by multiple sclerosis. Eur J Neurol 2007;14:290-296.

-6 Collin C, Ehler E, Waberzinek G, Alsindi Z, Davies P, Powell K, Notcutt W, O'Leary C, Ratcliffe S, Nováková I, Zapletalova O, Piková J, Ambler Z: A double-blind, randomized, placebo-controlled, parallel-group study of Sativex, in subjects with symptoms of spasticity due to multiple sclerosis. Neurol Res 2010; 32:451-459.
7 Novotna A, Mares J, Ratcliffe S, Novakova I, Vachova M, Zapletalova O, Gasperini C, Pozzilli C, Cefaro L, Comi G, Rossi P, Ambler Z, Stelmasiak Z, Erdmann A, Montalban X Klimek A, Davies P; Sativex Spasticity Study Group: A randomized, double-blind, placebo-controlled, parallel-group, enriched-design study of nabiximols* (Sativex $\left({ }^{\circledR}\right)$ ), as add-on therapy, in subjects with refractory spasticity caused by multiple sclerosis. Eur J Neurol 2011;18:1122-1131.

8 Wright S, Vachova MM, Novakova I: The effect of long-term treatment with a prescription cannabis-based THC: CBD oromucosal spray on cognitive function and mood: a 12 month double blind placebo-controlled study in people with spasticity due to multiple sclerosis [Poster 1206]. Mult Scler 2013;19(suppl 1): 559-573. 